\title{
Urban Water Hydrological Modelling
}

\author{
Pooja Shrivastava \\ Research scholar, Department of Civil Engineering \\ National Institute of Technology, Raipur
}

\begin{abstract}
Urban water hydrology is a science part of hydrology investigating the hydrological cycle and its change water regime and quality within urban areas and its impact on various sectors . It includes urban water infrastructure system that is complex and dynamic. The problems in urban water addressed towards the complex water related interactions which requires adoptable, sustainable and management strategies to maintain existing services and provide new ones. In this multifaceted urban environment, modelling tools are needed to support system's performance under different future scenarios. This paper significantly address the urban water hydrological modelling tools and reviews the different types of modelling tools are currently present . It also reflects the importance and challenges of urban water management and explores the potential way towards the new generation of modelling tools. In this paper also models are compared to find out the relevant models for urban water hydrological modelling.
\end{abstract} Keywords: urban hydrology, modelling, urban water system, urbanisation.

\section{INTRODUCTION}

Urbanisation is a rapid and intensive transformation in present century. Global changes and the framing of additional urban water management objectives along with recycling of water, water supply and delivery, climate improvements, food security using green water infrastructure have now single optimisation (Erbe and Schutze, 2005). For that reason sustainable urban water management is a considerable idea in the cities includes ;(1)manage the urban water cycle on the worldwide base;(2) provide an alternative technologies to meets the demand of the urban hydrology; (3) develop models to optimise each levels locally and globally. The ever increase stress of urbanisation demands the sustainable water management strategies and utility provision for government and organisations. As a result there is a increasing in demand for better use, productivity, flexibility, robustness and quality of urban water modelling system. Modelling the urban water hydrological system has progressed along with the same path as management. So there is urgent need for better order in modelling techniques and an assessment with the objective of integrated modelling in urban system. In this paper briefly describes the models for urban water and integrated modelling, to identify the future modelling requirements and directions. This integrated modelling of the urban water is aim to evaluate the different strategies and scenarios for management and framework at the planning level. Better understanding of this complex urban water modelling requires an important change in the approach to simulation modelling.

The objective of the paper aim to;

\section{OBJECTIVES}

1. To understand the integrated urban water hydrological modelling in urban water system.

2. To identify the clear difference between types of urban water models and its modelling.

3. To state an adaptation of integrated urban water hydrological models.

4. To explore the importance of modelling in future.

\section{III.URBAN WATER HYDROLOGY}

Urban water hydrology is the interdisciplinary science of water and its interrelationships with urban people(Jones, 1971). It should also understand a distinct application of the hydrology in the urban region because of consideration of human activities with air, water and land. It is also a special case of hydrology for cities which are highly interference by human activities (Janusz 1999). With the growing unpredicted human population, urbanisation influences the surrounding areas which effects urban hydrological cycle and environment of metropolitan areas. This urban water hydrology includes the factors which affecting the urban environment such as precipitation, surface runoff, groundwater and receiving water bodies. To avoid hazards to the urban environments it is need to be urban water management strategies should be carried out by the using remote sensing and GIS techniques.

Current issues of urban hydrology: It deals with the relationships between social and economic factors in the cities. The costs of providing urban water services are rising which depends on the high degree of water treatment. Storm water or urban runoff also play an important role added to the urban water hydrology which deals with the problem of tremendous amount of water causing heavy water pollution with contaminants flushes in the city roads. This added the problems of disposal of solid waste in the pits and landfills which causes severe 
problem of the groundwater as well as leaching in the surface. Another problem associated with the construction of road ways and house which may expose the soil contaminants and this may accelerate the erosion which chokes the drainage system of the city due to sediments and fills. The urban drainage system is highly uneven in terms of various characteristics such as slope, size, shape, roughness and degree of imperviousness.

There are some serious urban water challenges; they are as;

1. Water demand, quantity and safety issues

2. Serious water shortage situation

3. Deterioration of water quality

4. Flood and droughts

5. Urbanisation

6. Waste water and sanitation system

7. Health issues

8. Degraded natural water resources

9. Poor governance policies

10. Impact of climate change

Activities under the urban water management include the following

- Improve water supply and consumption efficiency

- Raise drinking water quality and efficiency of wastewater treatment

- Increase economic competence of services to sustain operations for water demand and supply , wastewater, and storm water management

- Employ alternative water sources, including rainwater harvesting, and domesticated and treated water

- Engage organisation to reflect their needs and knowledge for water management

- launch and implement policies and strategies to facilitate the above activities

- Support capacity improvement of personnel and institutions that are engaged in urban water hydrology

\section{IV.URBAN WATER HYDROLOGICAL MODELLING}

In water resources engineering modelling defined as simple representation of a complex system. Models always describe the basic and most important components of a complex system (Dooge 1977). The fundamental classifications of modelling are hydrological modelling to estimate the peak discharge and hydraulic modelling to estimate the water surface elevation. Urban hydrological modelling involves simulation of hydrological processes of the urban catchment to derive runoff required for the design of appropriate water drainage system. Trends in urban water models is thus towards the models which are enhanced to represent the spatial and temporal dynamics of the rainfall-runoff response.

Urban hydrological models can be classified according to two general criterions;

1) Spatial resolution: Models are either lumped or spatially distributed Lumped models do not explicitly take into account the spatial variability of parameters. They are usually structured to utilize average values of the catchment characteristics to determine runoff at the outlet of the catchment. Lumped models ignore the internal spatial variations flow and provide the stream flow only at the outlet of the catchment.

Distributed models can account for spatial variations in parameter and state variables within the catchment. In these models, catchment is divided into elements (by a grid) and precipitation, infiltration, evaporation and other catchment processes are modelled and overland flow, soil moisture is computed at element level.

2) Time scale: Event based and continuous model

Event based model: Model Used in design of drainage infrastructure and thus used to represent hydrologic behaviour for a design storm, to estimate flows due to given storm event and used for deciding design flows of systems components.

Continuous model: Models are used in time series to represent long term behaviour through a variety of rainfall events and dry weather periods and therefore have broader potential application; to derive long term continuous flow; to understand the long term variations of flow.

Models for sustainable urban water management of urban runoff: The concept of the sustainable water management modelling is an integrated approach to make interactions between the different elements of urban 
water system i. e. Maintain public health and hygiene prevent drought and flood, preserve environment, sustain water quality and lastly influence of urbanisation on hydrology of city area. It needs the integrated modelling used by the policy makers for decision making frame-work. The behaviour of part of the system with respect to the whole system is easily provide by integration technique with consideration of each component processes (Beck, 1976). These integrated models are epistemological devices and holistic tools for decision making management, planning and policy (Mcintosh et al., 2007). The four major application of integrated models are ; 1.Modelling exploration 2.Building of theories 3.Scenarios for testing 4. Provide information for straight planning and management. There are 16 types of integrated hydrological models are presented for urban water modelling; are as follows:

1. MOUSE: Mouse is software used for modelling drainage system to stimulate the surface runoff, water quality and sediment transports in the urban areas and drainage system. It is dynamic; user friendly modelling tool can be applied to analysis, design and management of pipe network, pressurised flow either with small pipers or large pipes. It usually provide efficient and complete environment for complicated urban drainage system. It is a spatially distributed mode with link node network and usually divides the catchment areas into number of contaminant generating land. It also has a capability to deals with dissolved oxygen and pathogens organisms in the streams.

2. AQUACYCLE: Aquacycle is a water balance continuous model that characterises the each components of the urban water hydrological system i.e. water supply and recycle, waste water and storm water (Mitchell et al., 2001). It takes input in the form of rainfall data and imported water which is circulate through the urban water cycle system and output will obtained in the form of evapo-transpiration, storm water quantity and waste water discharge. In this model storm water and waste water can be store separately and used in the source of supply in the non-potable water applications. By using this model reuse schemes applied on the storm water and waste water with the measurement of parameters such as average unit block occupancy, average block size, average garden size, average roof area, average paved area, average $\%$ of garden irrigated, number of unit blocks, cluster area ,leakage from the reticulation system, road area within the cluster ,Cluster storm water output flows into cluster number, cluster waste water output flows into cluster number, public open space area within the cluster, $\%$ public open space irrigated and Catchment area.

3. P8-UCM: Model used for evaluating the generation and transport of storm water runoff pollutants in urban areas. Modelling based on the continuous water balance and mass based equation in the user defined system. P8-UCM simulations are driven by the continuous hourly rainfall and daily temperature series. Its primary applications found in the best management practices of the urban water design to achieve total suspended solids removal efficiencies (75-80\%). Mainly simulations techniques are detention ponds (dry and wet), infiltration basins and buffer regions.

4. BASINS: BASINS (Better Assessment Science Integrating point \& Non-point Sources) is basic model used in the watershed management, evaluating the total maximum daily loads, coastal zone management, non-point sources, water quality parameter modelling and also in national pollutant discharge elimination system. It provide information to the users included national environmental information and allow to access planning tools, robust non-point loading and water quality models. GIS (geographic information system) work for single integrated framework with the BASINS and display output such as discharges, water supply withdrawals, point sources and land uses-land cover.

5. EPANET: The most popular software for water distribution system modelling developed by the United States Environmental Protection Agency's (EPA). It performed well in the simulation of hydraulic, water supply and water quality in the pipe network. It reaches the next level of improvement in the potable water constituents in the distribution systems. It also supports the simulation of spatially and temporally a variation in water demand and provides output information such as pipes flow, junction's pressures, contaminants properties, and chlorine proportion.

6. Hydro-planner: Hydro-planner supports the simulation of storm water, runoff, water supply and demands, reservoir storage levels and routing for the stream network. It is integrated modeling system for the total urban water cycle. It consist of seven different modules; such as catchment module for simulate runoff in the catchment, water supply module for simulate water supply system, consumption module for stimulate the urban water consumption, storm water module for stimulate storm water, waste water module for simulate for waste water, receiving water module for stimulate flow and routing of receiving water, integration module for computation of input and output data between different modules. 
7. ILSAX: ILSAX is very suitable software for urban catchment modelling and designing but it requires calibration with available flow data (Sunil 2000). It need the hydrological data, physical properties of the catchment areas and storm water drainage system details for modelling the urban catchment In this model input parameters are divide into two groups; one group deals with the rainfall parameters and other group deals with routing parameter of previous and impervious areas. Two files are prepared as input i.e. run and rain file and another pipe file. Run and rainfall pipe provides information such as catchment soil type, depression storage values where pipe file contains the storm network details.

8. MUSIC (Model for Urban Storm water Improvement Conceptualisation): MUSIC is a spatially distributed model with a link node drainage network design to help the urban water storm and its pollution impacts. It has smallest time steps of 6 minutes so it has limitation of predicating the flow rates from the smaller areas less than $0.01 \mathrm{~km}^{2}$. It uses daily calculations to determine the amount of runoff and routing represent the drainage link. It consider as single lumped groundwater reservoir in each small divided catchment and also uses the hydrologic routing in a drainage network.

9. PURRS (Probabilistic Urban Rainwater and Wastewater Reuse Simulator): This model investigates the mains water savings and storm runoff when the decentralised approach used in the cities. In this model two integrated water cycle management option are available in the form of demand management and rainwater tanks. It does not include any type of routing and also not treat the catchment in a lumped fashion with no drainage.

10. IQQM (Integrated quantity and quality model): It is also a generic model to integrate the water quality and quantity and designed for examine long term variations. It will eventually consists of four main components such as an in stream water quality modules, as in stream water quantity module, a rainfall-runoff pollution and generation module and ground water quantity and quality module. It provides the more reliable information relating issues such as environmental flows and water quantity parameters.

11. RUNQUAL: It is a continuous daily simulation model used to estimate runoff volumes and quality and contaminant loads from the previous and impervious surface and quality from sites. In this model there are more than 2 contaminants are needed at the catchment sites and also have no drainage network in the lumped fashion. These resulting contaminants are routed through the best management practices which modify its characteristics before discharge from the site.

12. SLAMM (Source Loading and Management Model) : SLAMM also called Sea Level Affecting Marshes Model designed for the changes in tidal marshes for most susceptible ecosystems to climate variations specially for the increased sea level that involved the wet conversion and shoreline alterations during long term sea level rise (Park et al.1989). It defined as the complex tree incorporating geometric and qualitative interaction is used to represent transfers among coastal classes.

13. SWMM (Storm Water Management Model): SWMM is a dynamic rainfall-routing simulation model used for single event or long term event to estimating the runoff quantity and quality, flow rate, flow depth and quantity of water in the each pipe of the urban areas and sub catchment. it is specially used for the long term simulation and dynamic flood routing. SWMM accounts for various hydrologic processes that produce runoff from urban areas. In routing portion includes the routing of runoff overland along with the pumps, regulators, pipes and channels.

14. UVQ (Urban Volume and Quality): UVQ is a simulation computer tools to assessment of the sustainability of the urban water and to estimate the water flows and contaminants loads. In this one major pillar of the model is to examine the sources of contaminants and their flow path in the urban water cycle. UVQ model is quasi-distributed models presents a picture of the catchment in spatial scale as s unit block, land-use and catchment.

\section{V.DISUCSSION AND CONCLUSION}

There are many urban water hydrological models have been developed but the idea model must control variations of demands at spatial scale and temporal scale. At present there is no single urban water model which acceptably meets the current and future needs of the urban cities. So it is better to use coupled model than single 
model at temporal and spatial resolution. In urban water hydrological modelling, required improvement and consistent in water quality in a sub-daily time step. This urban water models needs to be address the following ; modeling all parameters of urban water cycle, calibrate and validate the urban water hydrological models carefully, water quality and quantity modelling with the objective functions, reliability and flexibility for the data resources and significant the goal of the model accuracy. There is significant scope for the recovering the potential of the models including; improving of runoff generation, ground water and contaminants elements , more integration for the receiving water and ecological affects, calibration an validation techniques with testing of model .

\section{REFERENCES}

[1] Beck, M.B. (1976) Dynamic Modelling and Control Applications in Water Quality Maintenance, Wat Res 10, $575-595$.

[2] Clark, R., Pezzaniti, D. and Cresswell, D. (2002) Watercress - Community Resource Evaluation and Simulation System - A tool for innovative urban water system planning and design, Proc Hydrology and Water Resources Symposium 2002, 20 - 23 May, Melbourne.

[3] Coombes, P.J. and Kuczera, G. (2002) Integrated Urban Water Cycle Management: Moving Towards Systems Understanding, Proceedings of the 2nd National Conference on Water Sensitive Urban Design, Engineers Australia, Brisbane, Australia.

[4] Gregerson, J.B. and Blind, M. (2004) OpenMI: The Essential Concepts and their Implications for Legacy Software, The International Environmental Modelling and Software Society Conference, 14-17 June, University of Osnabrück, Germany.

[5] Gujer, W., Krejci, V., Schwarzenbach, R., \& Zobrist, J. (1982) Von der Kanalisation ins Grundwasser - Charakterisierung eines Regenereignisses im Glattal. GWA, 62(7), 298-311.

[6] Hardy, M.J., Kuczera, G. and Coombes, P.J. (2005) Integrated urban water cycle management: the UrbanCycle model, Wat. Sci. \& Tech., 52(9), 1-9.

[7] Maheepala, S., B. Leighton, F. Mirza, M. Rahilly \& J. Rahman (2005) Hydro Planner - a linked modelling system for water quantity and quality simulation of total water cycle. In Zerger, A. and Argent, R.M. (eds) MODSIM 2005 International Congress on Modelling and Simulation.Modelling and Simulation Society of Australia and New Zealand, December 2005, pp. 170-176.

[8] Mitchell, V. G., Mein, R. G., McMahon, T. A., (1998) Performance of Aquacycle, a model of the Integrated Urban Water Cycle. HydraStorm 98, International Symposium in Stormwater Management, Adelaide, 27-30 September 1998, pp 183-188.

[9] Mitchell, V.G., Mein, R.G., \& McMahon, T.A. (2001) Modelling the Urban Water Cycle. Journal of Environmental Modelling \& Software, Vol. 16 (7) pp 615-629.

[10] Mitchell, V.G. and Diaper, C. (2005) UVQ: A tool for assessing the water and contaminant balance impacts of urban development scenarios, Wat. Sci. \& Tech., 52(12), 91-98.

[11] Mouritz, M.J. (1996) Sustainable Urban Water Systems: Policy and Professional Praxis, Unpublished PhD Thesis, Institute for Science and Technology Policy, School of Social Science, Murdoch University, Perth.

[12] Rauch, W., Bertrand-Krajewski, J.-L., Krebs, P., Mark, O., Schilling, W., Schütze, M. and Vanrolleghem, P.A. (2002) Deterministic modelling of integrated urban drainage systems, Wat. Sci. \& Tech., 45(3), 81-94.

[13] Roberts, P. (2005) Yarra Valley Water 2004 Residential End Use Measurement Study. Schmitt, T.G. and Huber, W.C. (2005) The scope of integrated modeling - system boundaries, sub-systems, scales and disciplines, 10th International Conference on Urban Drainage, Copenhagen, Denmark, 21-25 August 2005.

[14] Schütze, M., Butler, D. and Beck, M.B. (1996) Development of a framework for the optimisation of runoff, treatment and receiving waters. 7th International Conference on Storm Drainage, Hanover, Germany, 9-13 Sept 1996. Stewardson, M., McMahon, T. \& Spears, M. (1995a) Krakatoa: A Model to Assist Integrated Water Resource Management Decision-Making in Urban Areas. AWWA 16th Federal Convention. Sydney.

[15] Stewardson, M.J., Clark, R.D.S, Cresswell, D.J. and McMahon, T.A. (1995b) Modelling to Assist Integrated Management of Urban Water Resources, In Second International Symposium on Urban Stormwater Management, July 11-13, Melbourne, Australia. 